\title{
Mediating Cultures between and among Arabic Teachers
}

\author{
Meriem Bousaidi Bacha \\ Fairfax County Public Schools, Fairfax, Virginia, USA \\ Marjorie Hall Haley \\ George Mason University, Fairfax, Virginia, USA
}

\begin{abstract}
This paper explores how Arabic teachers participating in a 2013 StarTalk program incorporated culture in performance-based assessments while mediating their respective cultures for teaching in US schools. The primary focus centers around how teachers mediate between their first culture and the cultures of the US as demonstrated in their micro teaching simulations. Promoting intercultural and cross-cultural competencies becomes a primary goal and objective for Arabic teachers in the US. We conclude and concur with the sentiments of Rings (2006): the teaching of Arabic must be deliberately focused on mastering cultural knowledge that exposes students to multiple authentic scenarios and assists teachers in mediating cultures between and among Arabic teachers.
\end{abstract}

Index Terms - culture, critical need languages, teacher development

\section{INTRODUCTION}

This paper explores how Arabic teachers participating in a 2013 StarTalk program incorporated culture in performance-based assessments while mediating their respective cultures for teaching in US schools. The primary focus centers around how teachers mediate between their first culture and the cultures of the US as demonstrated in their micro teaching simulations. The United States Department of State issued a call for the need for "highly qualified" world language teachers in "critical need languages." Arabic is one of the languages that falls into this category. In response to this call our teacher education program has actively sought ways to respond by providing multiple opportunities to fill a gap. StarTalk is a component program of the National Security Language Initiative (NSLI). The initiative seeks to expand and improve the teaching and learning of strategically important world languages that are not now widely taught in the United States. StarTalk's mission is to increase the number of Americans learning, speaking, and teaching critical need languages by offering students and teachers of these languages creative and engaging summer experiences that strive to exemplify best practices in language education and in language teacher development, forming an extensive community of practice that seeks continuous improvement in meaningful assessment of outcomes.

Our university is a large public institution with more than 32,000 full time equivalent (FTE) students, located just outside Washington, DC. The Graduate School of Education is part of the College of Education and Human Development in which the Foreign/World Language Licensure program offers PK-12 teaching licenses. Thanks in large part to generous grants from StarTalk, we have been able to sponsor six summer institutes for Arabic and Chinese teachers. The sixth summer institute (2013) and the Arabic teacher participants are the focus of the present paper.

\section{THE STARTALK SUMmer INSTITUTE}

The 2013 summer institute, "Creating The Authentic Assessment Toolbox for Today's Learner-Centered Classroom," provided three weeks of critical methodological training in transitioning teachers to learner-centered instruction for today's millennial learners. Fifteen Arabic pre and in-service teachers engaged in carefully structured learning sequences including face-to-face and online blended communities of practice. Week one consisted of varying reading tasks, selected scholarly articles on assessment, and viewing best practices videos. Week two was comprised of a series of professional development workshops focused on creating an authentic assessment toolbox. This included learnercentered approaches to language teaching as highly effective tools for addressing pedagogical issues inherent in less commonly taught languages. Workshop topics included, "Effective Planning for Assessment In a Standards-based Classroom;" "Integrated Performance Assessment;" "Standards-based Learner Centered Assessment;" "Formative Assessment;" "Summative Assessment;" and "Technology-based Assessment." On days five and six of this week, teacher participants conducted two thirty-minute micro teaching demonstrations with students attending a simulated children's camp in Arabic. This provided opportunities to connect theory to practice. Week three was a continuation of online blended learning activities using the Ning as a social mediated platform. (Ning is an online platform for people and organizations to create custom social networks.)

Mediating Between Cultures as Observed in the Micro Teaching Simulations 
Although Arabic Startalk participants struggle with newly learned concepts, they were determined to become effective teachers. Both returnees and new participants at the Startalk workshop shared the same goal: their classrooms would no longer focus only on grammar and vocabulary, but also on building communicative competence. They were aware that linking the standards for learning languages to both the assessment and to the curriculum would develop the critical awareness needed to compete in the global multicultural environment ${ }^{1}$. Mastering the new teaching approaches would enable participants to plan meaningful lessons and assessments that match the millennial students' awareness of the digital world and their need to fulfill the citizen of the world status. However, this itinerary was fraught with obstacles.

The first issue this paper will focus on is the rising of the cultural "dimension" as a barrier to understand and apply effective teaching methods, particularly the Integrative Performance Assessment (IPA) ${ }^{2}$. Integrating the three modes of communication in an assessment that shows what students can really do in an authentic environment raises another issue, which is linked to the status of the Modern Standard Arabic (MSA) in the Arab world. The second issue deals with how Arabic teachers bridge the gap in teaching MSA in the absence of a "native speaker" of the Arabic language.

Often the concepts addressed in Startak workshops are difficult for the Arabic participants to understand, especially for those who have switched to the teaching career from some other profession. A one week workshop onsite and another one on-line are not enough to assimilate such highly condensed notions, let alone integrate them into lesson plans. Most of the Arabic education specialists recognize that the explanation and the translation of these concepts into Arabic are challenging because this is a new field for Arabic pedagogy. Arabic experts are still working on coining the terminology, for example, while some experts call the interpersonal mode of communication الصورة التبادلية (exchange approach), others call it الصورة الحوارية (dialogue approach). Sometimes the meaning is lost in the translation.

The participants' pattern of cultural thinking was another challenge, often slowing down the understanding of these concepts. It is known that communication is impacted by each individual's or group's set of values and behavior. Blake, Walker, and Walker (2003) captured the cultural behavior existing worldwide in ten dimensions ${ }^{3}$. The three most significant cultural orientations that impact directly the participants' learning in the Startalk workshop are: structure, thinking, and communication. These three aspects are not stereotypes, nor negative cultural traits. They have been developed in the cultural neuroscience field to promote the intercultural awareness leading to the learning styles that make part of a community construct to which each community reacts to.

As far as structure is concerned, most participants showed that they are "order and structure oriented" and needed thorough instructions to guide them in their tasks. This may be tied to their political experience with dictatorships where conformism is praised at the expense of personal initiative in most fields. Therefore, people become more passive and expect to be given directions to follow. This became evident in the lesson plan writing procedure, where teachers had to be instructed step by step in crafting it. Teachers were provided with an English StarTalk lesson plan template that the master teacher had translated into Arabic. However, this was not sufficient, as will be explained later. The participants often confused the different modes of communication and how they should be addressed. In general, while new participants struggled with choosing what to teach or not teach from a specific topic or theme, the returnees seemed to be more comfortable with this phase.

\section{Cultural Variables in Task Design}

Most returnees were familiar with backward design (a method of designing educational curriculum by setting goals before choosing instructional methods and forms of assessment), but they still seemed to have difficulty preparing tasks to demonstrate evidence of students' learning. These teachers knew how to start with the end in mind to determine which direction their lesson should follow. However, it took them time to come up with evaluating tasks for assessing their students' understanding of a given topic.

In one group we observed that Middle Easterners ${ }^{4}$, North Africans and Chinese ${ }^{5}$ tended to be deductive thinkers. They focused on general ideas rather than on details. Using a deductive approach was not a negative quality since most mathematic reasoning relies on deductive thinking to show that the facts are true. However, this cultural variable

\footnotetext{
${ }^{1}$ The accelerating degree of contact and exchange among cultures is redefining our worlds and posing... challenge.” Blake, Walker, and Walker, Doing Business Internationally, The Guide to cross-cultural success, New York, McGraw Hill, 2003

${ }^{2}$ Integrated Performance Assessment (IPA) is also referred to as Performance Based Assessment (PBA), and Thematically Organized Assessment (TOA).They all refer to assessments which are integrated in one another because they feed into each other. They follow the same theme in this way they provide the student with knowledge, content and experience upon which the next assessment would depend. Paul Sandrock, The Keys to Assessing Language Performance, The American Council on The Teaching of Foreign Languages, Alexandria, VA, 2010.

${ }^{3}$ The other dimensions are: environment, time, action, communication, space, power, individualism, competitiveness, structure and thinking.

${ }^{4}$ Blake Walker \&Walker include in the Middle East Arabs North Africans. Though these regions underwent the same early European colonization wave in the late 1800 and early 1900, after the fall of the Ottoman Empire, they are still distinct from one another. First, the colonizing cul tures were themselves different and this was reflected on the colonized societies. While France colonized Morocco and Algeria, Britain colonized most of the Middle Eastern countries. Second, North Africans do not consider themselves as Middle easterners. The Berber communities, who are the native populations of Morocco, Algeria, Tunisia and Libya, were submitted to the "arabization" process that happened with the Muslim Conquest around the $640 \mathrm{AD}$ after the Prophet's death. Berbers preserved their language and still speak it in Morocco, Algeria, and Tunisia. In some regions Berbers do not speak nor understand Arabic. The Berbers do not consider themselves as Arabs and they still advocate for teaching Berber in schools. There is another problem that pertains to the whole educational system in Morocco for example. It underwent a whole process of arabization in schools and administrations from the French language years after the French left.

${ }^{5}$ Jin Wang, Culture Differences and English Teaching, English Language Teaching, Vol. 4, No. 2; June 2011, pp. 223-230. Available at www.ccsenet.org/elt
} 
explains why it was difficult for participants to put a multilayered structure, such as the communication modes or the IPA, in practice in a short time even when it was scaffolded for them.

The lack of critical thinking in the Arabic educational system, which is an issue in other nation systems, such as China, contributed to some of the difficulties that participants encountered. Very often, new participants confused proficiency and achievement objectives. However, the nature of the practicum at Startalk makes it hard for participant to plan attainable objectives, assessments, or a theme's logical sequence for students they did not meet yet. The 2013 StarTalk teaching simulations were challenging because participants were asked to write communicative tasks for a heterogeneous class.

The 2013 StarTalk participants modeled some qualities that teachers would like to see in their classrooms. They cared for each other and showed strong teamwork relationships. While this could be true, there should be caution about idealizing this show of friendly cooperation by taking into consideration the intricacies of social relations and social stratification that are at play in the region. This could be attributed to the "indirect communication" dimension displayed in these groups' interaction. Arabs tend to reinforce "conflict avoidance" and "face saving." Any direct communication may be viewed as aggressive, bad mannered, and lacking in courtesy.

During the feedback sessions, which followed the mini lessons, the observing teachers did not avoid pointing out their criticism to their peers in a direct way. However, there were other aspects that were made understood implicitly, such as making sure that the Sudanese participant knew that her dialect was not as good as others. Thus, it should not be used in the classroom, while theirs can be allowed. There is an issue among Arabs about the sense of "ownership" and "mastery" of the Arabic language. For example, the North African Arabic, according to some Middle Easterners, has been "compromised" by the influence of the Berber language. Linguistically speaking, languages cannot escape the influence of the invading cultures and this is true for all Arabic dialects.

This shows that "the cultural process" is often subtle and complex. Culture makes things understood without being stated. Very often, it was not easy for the master Arabic teacher to understand what the participants needed when they stated it indirectly. She could not take at face value what some participants said. Sometimes they were embarrassed to say they did not understand. For example, Arabs would never admit their lack of knowledge.

A recurrent question asked while writing a lesson plan was the number of new words that participants should include in each lesson. Participants were encouraged to consider the standards for learning languages and to focus on the communication purpose in context. Once the objectives of the communication modes were defined, it became easier to plan an assessment to determine what type of mastery they wanted to evaluate. Only then did it become clear for them which semantic or syntactic items should be included to achieve mastery.

Returning teacher participants usually showed full mastery of the standards for learning. They could write clear objectives and match them with engaging activities. However, they still could not determine the purpose of the communication. While technology was strongly apparent in their planning, the cultural objectives were not achieved because the various modes of communication were not linked together.

\section{Understanding Communicative Modes and Integrated Performance Assessment}

When it came to writing on-line tasks for the communication modes or the Integrative Performance Assessment (IPA), participants, new and returnees, did not seem to have grasped these concepts yet. They did not realize that the three modes of communication are but a duplicate of what we do when we are communicating with one another in the real world, and that we try to create a simulation of the real world to build those skills in our students. Participants sometimes confused simple activities carried out during the guided practice phase with the integrated tasks of the IPA scenario. Participants mistook simple activities carried out during the guided practice phase with the integrated tasks of the IPA scenario. One reason for this confusion was that they did not have enough time to do a scaffolding writing process that would take them from IPA to lesson planning. Their focus was on the standards, lesson objectives, and the vocabulary. They did not have time to write a different lesson plan to build up a unit which would allow for writing an IPA. They often confused the activities of the guided practice with the final IPA tasks.

To have a clear idea about how participants confused the communication mode activities and the IPA tasks, we provide samples below. One of the new participants identified the strategies of the three modes by writing that in the interpersonal mode, the teacher asks questions and the students provide answers; in the presentational mode, the students recite a poem, and in the interpretive mode, the students write answers to questions. When the teacher participants did not understand a newly taught concept, they would go back to what they know best: their experience. It was hard for participants and sometimes for foreign language teachers in general, to break away from what they had experienced for years as students. Interaction was inhibited in the Arab traditional education and critical thinking strategies were often replaced with memorization which is still practiced in many Arab countries today.

The next sample quoted below shows that some learning process of the three modes of communication was taking place but not materializing yet. The three modes of communication that were carried out during the mini lesson are highlighted. They represent, respectively, the interpersonal, presentational, and interpretive modes:

Interpersonal Mode: Teaching Vocabulary specifically the words of different animals. Each animal would be matched with its picture and an interactive game would be done be between the students where I would say the animal word (showing the picture) and the students would make the animal sounds. With this game all students participate so it is viable for a multi-level class. 
Presentational Mode: A game where kids sing a song that I have taught them that are about the new vocabulary words so that the kids can have fun while they are learning. I teach K2 and first grade so this method is a way to get them involved in the learning process presentational.

Interpretive Mode: Using cards: The children are in groups where they take turns pulling out cards. The cards have a picture of what the vocabulary word represents and they will then say it out aloud. This goes well in a multi-level class because the lower level students can learn from the group as they play along.

The participant described the activities she provided her students in the mini lesson. She seemed to have remembered only the "presentational" term, but not the others. Maybe the other modes' definitions were not clear for her. Actually, there was a discrepancy between what the participant taught and what she wrote above. The activities displayed in her class included engaging moments focusing on receptive and productive skills for all levels. First, she had students stand in line facing each other and take turns exchanging animal sounds and names. She tried to differentiate her "interpersonal task" by dividing the class into groups of three. She had the "novice low" students produce bird sounds and the "intermediate" students ask and answer questions about birds, talk about their favorite birds, and describe them (always prompting students with questions). She created the opportunity for all students to develop their receptive and productive skills. She allowed "intermediate" students teach the "novice low" students the new words while modeling for them.

It was difficult for the observing participants to determine which of the modes were displayed in the practice. During the discussion that followed the micro teaching simulations, only a few of the teacher participants identified the modes they actually used. Below are the summary notes of one of the new participants who commented on the Ning on the micro teaching simulation:

- During our lesson demo, last week, our team's objectives were:

- The students would be able to recognize the names of five birds (duck, pigeon, bird, chicken, and rooster).

- The students would be able to identify these birds' different colors, sounds, foods, and habitats.

Our activities were designed accordingly to meet these objectives. Participant1 used the "magic bag" activity to introduce the names of the birds. Participant2 used different games to introduce the colors. Participant 3 "created" her own song of these birds (both teachers and students enjoyed it big time! Good job Participant3!". She also used different games to introduce the birds sound. I ended this lesson introducing their foods and by making a closing project consisting in making a bird's nest. The students in the end were able to produce an IPA by talking about their project and also like the video activity as an interpretive one since students are going to identify the meaning of the video through strategies that you prepare in advance such as the questions that Paul Sandrock has introduced in his presentation. This is a summative assessment so students should have complete mastery of the topic before they listen to the video and answer your questions.

The participant showed mastery of writing objectives but could not express adequately what she did in her performance. Her activities were engaging too. She confused the fact that summative assessment comes at the end of a given unit and not a topic. As for the interpersonal and the presentational modes, she identified them as "talking about the project."

The returning participants collaborated with the two other groups and included a good link to the lesson and performed engaging, receptive and productive activities for the interpretive mode. Their topic was about animals on the farm. In the interpretive mode, the students succeeded in answering questions about the visuals they were shown. In the presentational mode, the students commented on their drawings, and in the interpersonal mode, the tasks were not so clear. Most of the speaking activities were either carried out individually or prompted by the teacher. The cultural standard took the aspects of pictures of animals popular in the Arab world such as the horse and the draumadory. Maybe participants did not have time to develop more meaningful cultural activities.

Importance of Meaningful Cultural Objectives

Another common feature of the participants' lesson plans was the lack of meaningful cultural objectives. Culture comes after communication in importance. Students have a full mastery of the language when they understand the context in which the language evolves. When participants were asked about their cultural choices, they often complained about the lack of teaching material. In fact, any authentic digital teaching material available was in dialect. This made it difficult for participants to transform the material they found into teaching material for developing interpretive, listening, or speaking skills in MSA. The teacher became the only source of MSA spoken language. Besides reading, students needed to listen to a language text to develop listening and interpretive skills. In Arabic classes, students are exposed to speech acts that are written in a manual and not acquired from an authentic context. Therefore, there remains a gap between what students acquire and what is going on in the real world.

Students do not acquire the knowledge or the skills that will turn them into native speakers. In explaining the speech acts, Halion refers to Derrida saying that "how words and expressions are understood is determined by how they are used throughout the community. But such uses vary from time to time and from place to place. There is nothing as permanent as to be accountable in terms of rules or to be determined as dependent on, or independent of, some other use." How can Arabic teachers develop intercultural competence in their students if they do not have the material to do so? This also raises the issue of the native speaker who speaks the same language that is being taught in class. The colloquial language in which most culture with (little c), is performed is not taught at school because it is the language 
of the street. Those who cannot read nor write MSA are called "illiterate" in Arabic. That is why participants and Arabic teachers in general, have problems finding audio visual authentic material in MSA targeting the Arabic native speaker when they address casual and personal themes. How can participants and teachers manage to mediate between MSA and dialect is discussed in the following section.

\section{Mediating Between MSA and Dialect}

The absence of material in MSA has been a significant issue during the StarTalk summer institutes. Teachers cannot find teaching material in MSA. Most interesting postings on YouTube come in dialects. Even in the news which tackles major topics in MSA, there is code switching when interviews and personal opinions are reported. In the last five years, some teachers tried to meet this need by posting material in MSA on YouTube, but it serves only the purpose of developing listening and speaking skills in the classroom. These videos show drastic modifications of the spoken language. Their language is slow and void of any natural socio-cultural characteristics. It is not an appropriate material for IPA because it is not authentic.

Most Arab speaking countries use dialects for colloquial communication and MSA as an official language for speeches, media ${ }^{6}$, academic purposes, and administration "correspondence." There are twenty six dialects in the Arab region. The following map shows how they are spread in the Arab World:

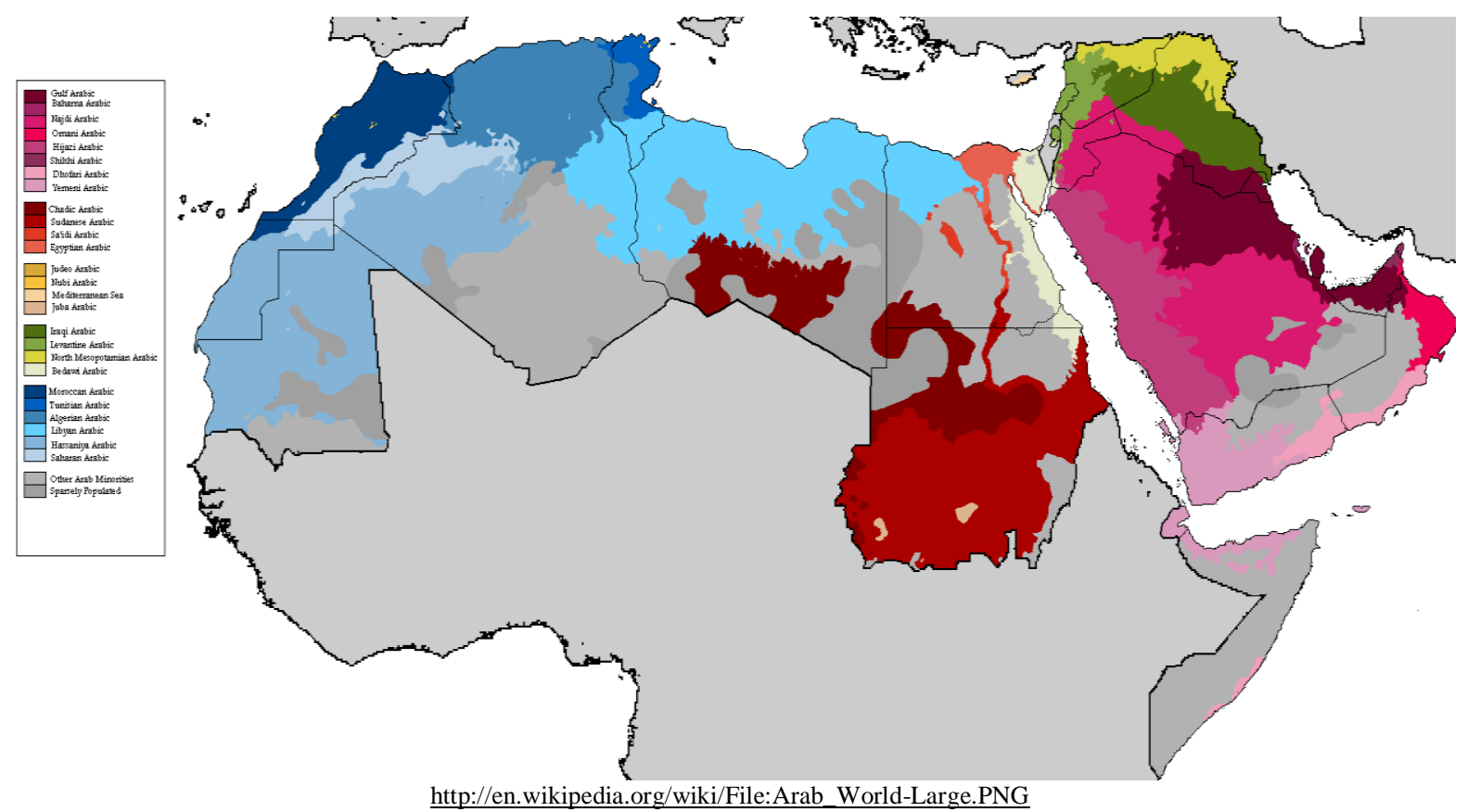

Sometimes we may find more than one dialect spoken in one country. For example, in Saudi Arabia, the spoken dialects are Najdi, Hijazi and the Gulf Arabic. The dialect itself has variants that differ from one region to another. In Morocco, for example, people of the plains struggle to understand mountain dwellers, referred to as "Jbala." Generally, every group of speakers in the Arab World proclaims to be the closest in their speech to MSA. There are many blogs that address and argue this matter.

Since cultural trends may raise communication barriers, it becomes clear that promoting the intercultural and the cross-cultural competencies are important. Functional linguistics has revealed that language is ambiguous, and ""shared" knowledge that speakers must have in order to communicate appropriately...is as essential to successful communication as are words and forms." Lana elaborated further that "it is this structured background knowledge, often culture-specific, that helps human beings interpret the language of others." ${ }^{7}$ How can students master that cultural knowledge if they are not exposed to it through various authentic scenarios? How can students understand the underlining cultural structure of a language if they are not exposed to it in its integral form? There are many topics that cannot be taught through a descriptive or a prescriptive approach. Students need to listen and interpret a text to find out those semantic and cultural markers that develop the speaker's socio-cultural competence of a language. If the teaching of the Arabic language is missing this fundamental part, which is the speaking, how accurate is IPA in Arabic? How can the interpersonal mode be authentic while it is carried out in MSA, which is not the language of the Arabic native speaker?

\footnotetext{
${ }^{6}$ For example, al-Jazeera programs are in MSA. When interviews occur in documentaries they are carried out in MSA but the interviewees generally speak in their dialects. The interviewers paraphrase in MSA. The Moroccan channel also mixes MSA comments with real people's interventions in dialect in programs. I still use those programs in class and give students a task to look for key words.

${ }^{7}$ Lana Rings, The Oral Interview and Cross-Cultural Understanding in the Foreign Language Classroom, Foreign Language Annals, $39(1)$, p.43.
} 
This problem does not exist in the Arab world because Arab students learn MSA academically and speak the dialect at home. When starting to teach languages abroad, instructors copied the same model. The problem was not imposing itself because only Eastern Arabs, mainly Egyptians, Lebanese, Syrians and Palestinians, used to teach in America. When Iraqi, Sudanese and North Africans joined the field, the dialect issue imposed itself. The public school system in America is not sensitive to this issue yet because MSA is taught exclusively and because district-wide assessments such as Performance Assessment for Language Students (PALS) includes the interpersonal mode only at level three, which is equivalent to the intermediate level. Besides, Arabic teachers are still struggling in making the Arabic language stand firm $^{8}$ in front of other electives and other languages that are traditionally established, such as Spanish and French. For example, there is only one pyramid for the Arabic language in the whole Fairfax County Public Schools.

This issue was more felt at the college level where the Arab instructors tried to handle this situation in different ways. For example, the al kitaab writers ${ }^{9}$ added lessons in dialects at the end of each chapter. Some colleges ${ }^{10}$ offered classes in pure dialects sustaining that they are solely responding to students' demands. Some think that teaching a certain variety creates a problem because the learner of a dialect will speak only the variety of a specific region within the same Arab country.

On the other hand, conservative scholars disapprove of these changes and define them as "patching hole" solutions. MSA is a written variety of the classical Arabic, which is the language of the Quran. Being a "light version" of the classical Arabic, it is more popular among the Arabs and thus used intelligibly among educated Arabs ${ }^{11}$. They think that it would be more beneficial to teach MSA for at least two or three years before allowing any dialect studying ${ }^{12}$. Teaching dialects without MSA will weaken its use in the United States and will not prepare the young learners adequately for the reality they may face in a given Arab country. They will not be able to read the media for example nor understand the news and most programs on TV.

We do not minimize the dialect teaching project as an endeavor to facilitate the mediation between MSA and other dialects because any attempt to facilitate teaching and learning Arabic in an accurate way should be encouraged and supported. However if the purpose is to teach Arabic, dialects should not be considered as a surrogate of MSA. Students can use their MSA background knowledge for intelligibility in any given Arabic country and develop proficiency in a given dialect in a faster time, but the contrary may not be true. This issue pertains to cinema in the Arab world too. The Arab movie producers are challenged by the language choice for movie dubbing to make foreign movies accessible to a wider Arab audience. While the notorious Syrian producer, al-Haitham al-Haqqui, believes that it is worthwhile to use the Egyptian, Syrian, or Lebanese dialect for the movie series and MSA for long motion pictures such as "Alexander," the Egyptian journalist, Tarik Saad, supports the use of MSA for all types of movies to avoid conflict about dialect choice among Arabs. In his opinion, this choice sustains the use of MSA throughout the region and makes it stronger ${ }^{13}$. Like Tariq Saad, we think that instruction in MSA should precede that of any of the Arabic varieties if students have the intention to develop proficiency in Arabic in general.

\section{CONCLUSION}

This paper grew out of the experiences of a master Arabic teacher and the program director of a federally funded teacher development program for critical need language teachers. Over the last six years our university's StarTalk programs' summer institutes have addressed a wide range of topics germane to preparing critical need language teachers for teaching in US schools. The topics have ranged from brain-compatible teaching and learning, assessment, transitioning to teaching in US schools, to differentiating instruction in a learner-centered, standards-based classroom. We have learned a great deal about the often complicated issues that these teachers and would-be teachers face in their professional development training. However, we continually recognize and acknowledge that culture is a broadly defined construct. One cannot simply talk about "a culture" or "the culture" of any group. Instead we must all be critically aware of viewing culture through a myriad of lenses. It is through these lenses that we are able to co-create empathy.

Given the breadth and depth of the Arab world, its many cultures and languages, the guiding force behind this paper was to situate one particular topic: mediating cultures between and among Arabic teachers. We set out to examine how teachers in this program incorporate their respective cultures while preparing to teach in US schools. During the course of the 2013 summer institute, we were interested in examining how these teachers mediated between and among cultures. Given that the topic of this particular institute was assessment, one goal was to investigate how teachers mediated between cultures as demonstrated in preparation for their micro teaching simulations. We highlighted two

\footnotetext{
${ }^{8}$ For example, there is only one pyramid for the Arabic language in the whole Fairfax County Public Schools.

9 "Alkitaabtextbook.com" is the home of the companion websites for the Al-Kitaab Arabic Language Program. The Al-Kitaab Arabic language textbook program, published by Georgetown University Press, uses a communicative, proficiency-oriented approach with fully integrated audiovisual media to teach modern Arabic as a living language. The series concentrate on developing skills in Modern Standard Arabic and spoken Egyptian and Levantine Arabic.

${ }^{10}$ The College of William and Mary, for example, offers classes in Arabic dialects.

${ }^{11}$ MSA is popular among Asian Mulims too in America because they learn the Quran

${ }^{12}$ Yale University follows this model

${ }^{13}$ www.alarab.com.qa/printarticle.php?docId=99767
} 
primary areas that were revealed: a rising of cultural dimension as a barrier in understanding and applying effective teaching tools, particularly use of the Integrated Performance Assessment; and how Arabic teachers bridge the gap in teaching Modern Standard Arabic in the absence of a native speaker of the Arabic language. The way information is received and comprehended was also a contributing factor. It can be argued that many of our participants were comfortable with instruction following "order and structure" orientation. Further, many of the teacher participants when planning lessons preferred to focus on general ideas rather than on specific details.

Finally, one of the most outstanding revelations and confirmations for us in doing this research highlighted the dearth of authentic materials and resources in Modern Standard Arabic. Today's Arabic teachers continue to struggle to locate truly "authentic" resources for use in their classrooms. The internet provides some useful tools but these are often fraught with errors and sometimes are culturally and linguistically insensitive. Promoting intercultural and crosscultural competencies becomes a primary goal and objective for Arabic teachers in the US. We conclude and concur with the sentiments of Rings (2006): the teaching of Arabic must be deliberately focused on mastering cultural knowledge that exposes students to multiple authentic scenarios and assists teachers in mediating cultures between and among Arabic teachers.

\section{REFERENCES}

[1] Austin, J. L. (1962). How to do things with words. Cambridge, MA: Harvard University Press.

[2] Blake, Walker, \& Walker. (2003). Doing business internationally: The guide to cross-cultural success. New York: McGraw Hill.

[3] Bram, M., \& Morgan, C. (1994). Teaching and Learning Language and Culture. Great Britain: WBC.

[4] Englebert, J. (2004). Character or culture? EFL Journal, 24(2), 37-41

[5] Galloway, V. B. (1984). Communicating in a cultural context. ACTFL Master Lecture Series. Monterey, CA: Defense Language Institute.

[6] Kramsch, C. (1993). Context and culture in language teaching. Oxford: Oxford University Press.

[7] Hadley, A. O. (1993). Teaching language in context. Boston: Heinle and Heinle Publishers.

[8] Leveridge, A. N. (2008). The relationship between language and culture and the implications for language teaching. [Online] Available: http://www.tefl.net (October 2011).

[9] Liddicoat, A. J. (2002). Static and dynamic views of culture and intercultural language acquisition. Babel, 36(3), 4-11

[10] Matsuda, M. (1999). Interianguage pragmatics: What can it offer to language teachers? The CATESOL Joumal, 11(1), 39-59.

[11] Neito, S. (2010). Language, Culture, and teaching: A critical perspective. New York: Routledge.

[12] Rings, L. (2006). The oral interview and cross-cultural understanding in the foreign language classroom. Foreign Language Annals, 39(1), 43-53.

[13] Robinson, G. L. (1985). Cross cultural understanding processes and approaches for foreign language, English as a foreign language and bilingual educators. New York and Oxford: Pergamon.

[14] Sandrock, P. (2010). The keys to assessing language performance: A teacher's manual for measuring student progress. American Council on the Teaching of Foreign Languages.

[15] Stern, H. H. (1992). Issues and options in language teaching. Oxford University Press.

[16] Thamasoulas, D. (2001). The importance of teaching culture in foreign language classroom. [Online] Available: http://www.Radicalpedagogy (October 2011).

[17] Tomalin, B., \& Stempleski, S. (1993). Cultural awareness. Oxford: Oxford University Press.

[18] Tomlinson, B., \& Musuhara, H. (2004). Developing cultural awareness. MET, 13(1), 1-7.

[19] Valdes, J. M. (1987). Culture Bound: Bridging the Cultural Gap in Language Teaching. Cambridge: Cambridge University Press.

[20] Wang, J. (2011). Culture differences and English teaching. English Language Teaching, 4(2), 223-230.

Meriem Bousaidi Bacha Ph.D.-- Dr. Meriem Bacha is licensed to teach K-12 Arabic, French, and Italian in Virginia. She is currently President of the Virginia Arabic Teachers Association (VATA), Board Member of FLAVA (Foreign Language Association of Virginia), and master teacher with Startalk at George Mason University since 2010. She was a tenured professor at the University Mohammed V of Rabat, Morocco. She taught pedagogy, trained teachers, and supervised them in their instruction. After moving to the United States, she taught at the American University and George Washington University as an adjunct professor before starting her itinerary with the Fairfax County Public Schools. She also served as a master teacher for the Egyptian teachers group at the American Councils for International Education in 2012

Marjorie Hall Haley, PhD -- Dr. Marjorie Hall Haley is tenured Professor of Education and Director of Foreign Language Teacher Licensure in the Graduate School of Education at George Mason University in Fairfax, VA. She is a former Spanish, French, German, and ESL teacher of 14 years. Dr. Haley holds a PhD in Foreign Language Education and English as a Second Language from the University of Maryland, College Park. She has also earned a Master's degree in education and advanced studies certificates from Towson University and Johns Hopkins University, respectively. In her 26th year at George Mason University, she teaches Foreign Language methods and ESL methods courses as well as doctoral courses in Brain-compatible Teaching and Learning, Bilingualism and Second Language Acquisition Research. In 2012, the Foreign Language Association of Virginia (FLAVA) awarded her its Marshall Brannon Excellence in Teaching Award, Post-Secondary. In 2002 George Mason University awarded her its Outstanding Faculty Award in Teaching. She currently serves as member of the Board of Directors of the American Council on the 
Teaching of Foreign Languages (ACTFL).Dr. Haley's research and publication record is wide. Her most recent books are, ContentBased Second Language Teaching and Learning: An Interactive Approach ( $2^{\text {nd }}$ Ed.) (2014) and Brain-compatible Differentiated Instruction for English Language Learners (2010). In addition, she is a featured scholar in the WGBH and Annenberg/CPB video, "Valuing Diverse Learners" available at www.learner.org 